\title{
Spatially explicit multimedia fate models for pollutants in Europe: State of the art and perspectives
}

\author{
A. Pistocchi , D.A. Sarigiannis, P. Vizcaino \\ European Commission joint Research Centre, via E.Fermi, 1. I-21027 ispra (VA). Italy
}

\begin{abstract}
A B S T R A C T
A review by Hollander et al. (in preparation), discusses the relative potentials, advantages and shortconings of spatial and non spatial models of chenical fate, highlighting that spatially explicit models may be needed for specific purposes. The present paper reviews the state of the art in spatially explicit chemical fate and transport modeling in Europe. We summarize the three main approaches currently adopted in spatially explicit modeling. namely (1) multiple box models, (2) numerical solutions of simultaneous advection-dispersion equations (ADE) in air, soil and water, and (3) the development of meta-models. As all three approaches experience limitations, we describe in further detail geographic information system (GIS)-based modeling as an alternative approach allowing a simple, yet spatially explicit description of chemical fate.

We review the input data needed, and the options available for their retrieval at the European scale. We also discuss the importance of, and limitations in model evaluation.

We observe that the high uncertainty in chemical emissions and physico-chemical behavior in the environment make realistic simulations difficult to obtain. Therefore we envisage a shift in model use from process simulation to hypothesis testing in which explaining the discrepancies between observed and computed chemical concentrations in the environment takes importance over prediction per se. This shift may take advantage of using simple models in GIS with residual uses of complex models for detailed studies. It also calls for tighter joint interpretation of models and spatially distributed monitoring datasets, and more refined spatial representation of environmental drivers such as landscape and climate variables, and better emission estimates. In summary, we conclude that the problem is not "how to compute" (i.e. emphasis on numerical methods, spatial/temporal discretization, quantitative uncertainty and sensitivity analysis...) but "what to compute" (i.e. emphasis on spatial distribution of emissions, and the depiction of appropriate spatial pattems of environmental drivers).
\end{abstract} Keywords: Spatially explicit fate models GIS

Data assimilation

Analytical solutions

Simplification

\section{Introduction}

In the last years, increasing interest has been raised by spatially explicit multimedia chemical fate and transport models for the assessment of chemical concentrations. In this contribution we do not advocate systematic use of spatially explicit models: a discussion of the circumstances under which it is worth using spatially explicit models as an alternative to simpler and more traditional non spatial models in chemical fate evaluation can be found in Hollander et al. (this issue).

We rather discuss here which spatially explicit models to use, depending on the purposes of the study, once it is clear that a spatial model is needed.

It is worth mentioning that models used at a large scale and fine resolution (e.g. a catchment, an urban area, a contaminated site) are usually implemented to provide answers to very specific questions grounding on a wealth of information, and particularly field surveys and local, ad hoc measurements, and are usually requested to target a much finer accuracy. Throughout the paper, we limit instead our discussion to models applied for assessments at a small scale and coarse resolution, e.g. a country or a continent, which are conceptually comparable to "evaluative" models adopted in risk assessment (e.g. EC, 2003, 2004; Brandes et al., 1996). Although these models ideally aim at simulating chemicals at a given location, they normally target trends and orders of magnitude rather than point-wise quantities; the latter may be in fact affected by local factors (e.g., the stack height of an atmospheric emission or the mixing volume at the outlet of a water emission, or the specific location of a sampling point used for model evaluation), which are normally excluded from models at coarser resolution. Therefore, criteria to assess whether a large scale model matches or does not match observations are quantitatively very different from the ones used for small scale models (for instance, a factor 10 and an explained variance of $50 \%$ are already reasonable performances at a small scale, while for a large scale model a factor higher than 1.5 and explained variance less than $70 \%$ may be unacceptable), and this derives from a qualitatively different expectation from the model results. 
It must be also pointed out that, as spatial distributions of contaminants can be reconstructed directly from monitoring data, through geostatistical estimation (e.g. Wackernagel, 1997), or other more recent techniques such as self-organizing maps (Kohonen, 1990; see also Pistocchi et al., submitted for publication), it is not uncommon to refer to such reconstructions as "models" as well. The discussion might be broadened to a large extent, but this is beyond our scope. In this paper we only focus on "causal" models, i.e. models predicting chemical concentrations given emissions (direct mode) or emissions given an observed concentration (inverse mode).

\section{Spatially explicit models between realism and simplicity}

\subsection{Eariy models}

Early spatially explicit models were developed in the 1990 s and early 2000 s, as rather coarse multiple linear box models each representing a region (Wania and Mackay, 1995; MacLeod et al., 2001), and were more conceptual schemes of possible mechanisms of environmental distribution of chemicals, than tools for the prediction of concentrations at a specific location. In this sense, they are rather similar to conceptual schemes such as the CliMoChem (Wegmann, 2004) and ChemRange (Scheringer et al., 2004a,b,c) models, aiming at describing not even a broad region as a box, but a more abstract entity such as a latitudinal zone on earth. Such models describe what Mackay (2001) calls "evaluative environments" and can only account for the chemical transfer between large regions, and for coarse-scale variability of landscape and climate.

\subsection{More recent models}

More recent models have attempted a more realistic description of contamination with reference to specific zones of more limited extension (Suzuki et al., 2004; Pennington et al., 2005; Prevedouros et al., 2004; MacLeod et al., 2005). In those cases, the region of interest was described through a more refined grid of cells with resolution of a few hundreds of kilometers, for each of which a mass balance was computed, considering local emissions, local removal mechanisms and transport to and from neighboring cells. This is done in practice by writing a system of linear equations in number equal to the grid cells, which are solved in a straightforward way for steady state (e.g. Pennington et al., 2005) or transient conditions (e.g. Suzuki et al., 2004). Parameters describing landscape and climate were assigned considering the actual geography of each cell, achieving thus some realism. However, these models cannot be regarded as "realistic" chemical fate simulators, for a number of reasons. In the first place, a common approach in the setup of these models is to specify landscape and climate parameters, hence inter- and intra-media transfer rates, as representative values constant in time, which hampers the possibility of capturing mechanisms of transfer strongly dependent on time variations of environmental processes which may be very relevant (Lammel, 2004). Adopting constant values for environmental removal rates may make of little use developing models more complex than steady state calculations (see von Waldow et al., 2008).

Another remarkable simplification that makes these models comparable with single box models is the high degree of simplification in describing the spatial variation of landscape and climate parameters, usually by providing an average value over a very large region. Moreover, intra-media transporting currents (such as the water discharge between two cells, or wind flows) are not always easy to estimate. In particular, while transport in the inland stream network is fundamentally unidirectional and one-dimensional, and advection is clearly dominant over dispersion, transport in oceans needs always (at least) a two-dimensional description, and the atmosphere may well require a three-dimensional description. Things are complicated by the importance that dispersion takes on advection in these cases. The representative transporting currents estimated in the above quoted models are likely to reproduce the correct order of magnitude of advection and dispersion removal rates, but cannot be used to describe spatial patterns arising from these mechanisms, such as contamination plumes from a source of emissions (see, for instance, the comparison between box models and atmospheric transport models presented in Hollander et al., 2008).

For these reasons, a similar performance of spatial and non spatial models is often highlighted (e.g. in the comparison of models for HCB and PAHs by Armitage et al., 2007).

\subsection{Complex transpost models}

To describe more complex spatial patterns of chemical transport, the full advection-dispersion equation (ADE; e.g. Pistocchi, 2008a) should be solved, considering a two- (for oceans) or threedimensional (for the atmosphere) field of transporting currents. For soils, the ADE is often solved in one (vertical) dimension. ADE models of very high complexity have been developed, such as DEHM-POP (Hansen et al., 2004), or MSCE-POP (Gusev et al., 2005). Lammel et al., 2007 , propose the use of such more complex models, with specific reference to the MCTM model, as tools to identify the mechanics of pollutant transport; the authors highlight that traditional box models may underestimate long range transport and overestimate sinks of chemicals in the environment, and should be therefore calibrated with benchmarks provided by such more complex models.

Complex models based on the ADE bring together what is considered as the most realistic method for each environmental compartment considered. Typically, these models have grown by adding soil and ocean compartments to an original atmospheric model, which makes them biased towards the atmospheric phase of environmental fate. The spatial patterns of contamination described by ADE-based models over large regions have a more realistic appearance, although their results have seldom been experimentally evaluated for chemicals other than conventional pollutants, due to the very limited monitoring data available.

Reliance on these models is based primarily on the reasonable performance of the ADE solutions in each medium separately, which has been tested traditionally at fine scale for soils (a plot or an experimental vertical profile), and at regional and even global scale for oceans and, most of all, atmosphere.

Despite their high degree of sophistication, these models have a number of weaknesses. First of all, notwithstanding their elegant mathematical formulation, they are not fully based on fundamental physical relationships; at steps, a number of empirical correctors are added which are in practice calibration parameters impossible to evaluate in the absence of experimental data. These correctors are particularly used at the interface between two media, e.g. in the description of volatilization fluxes, often represented through a "series of resistances" analogy (e.g. Schwarzenbach et al., 1993) the parameters of which are only derived empirically. Understanding the limited physics behind even rigorous solutions to the $A D E$ in the context of environmental modeling has stimulated criticism towards claims of their being "physics-based", in favor of a more modest but philosophically conscious definition of "mediating models" (see e.g. Morton, 1993, and Beven, 1996, for a more thorough discussion).

Another aspect not to be neglected is that all numerical solutions to the ADE carry some unavoidable artifacts, among which maybe the most important one is numerical dispersion (e.g. Zheng and Bennett, 1995). This phenomenon depends on the resolution of the numerical grid of models in relationship to the celerity of transfer of perturbations, and may be of the same magnitude as physical dispersion in the environment. A demonstration of the equivalence between grid resolution and assumed "physical" dispersion, and its positive exploitation in modeling, is provided by Sukop (2001), with reference to soil contaminant modeling. 
Table 1

Meaning of the terms R, D and the type of distance, for Eq. (4) applied to different media,

\begin{tabular}{llllll}
\hline $\begin{array}{l}\text { Environmental } \\
\text { compartment }\end{array}$ & $\begin{array}{l}\text { Dominant } \\
\text { dilution } \\
\text { mechanism }\end{array}$ & $\xi$ & $w$ & $\begin{array}{l}\text { Dilution } \\
\text { function, } D\end{array}$ & $\begin{array}{l}\text { Decay } \\
\text { function, } R\end{array}$ \\
\hline $\begin{array}{l}\text { Stream } \\
\text { network }\end{array}$ & Advection & $\begin{array}{l}\text { Curvilinear } \\
\text { abscissa on } \\
\text { the stream } \\
\text { network }\end{array}$ & $\begin{array}{l}\text { Stream } \\
\text { (input map) }\end{array}$ & $\alpha(\xi)$ & $e^{-k \xi}$ \\
Atmosphere & Dispersion & $\begin{array}{l}\text { Euclidean } \\
\text { distance }\end{array}$ & $\begin{array}{l}\text { Suggested } \\
\text { constant } \\
\text { value: } 3 \mathrm{~m} / \mathrm{s}\end{array}$ & $\alpha_{0} \xi^{b}$ & $e^{-k \frac{\xi}{w}}$ \\
Soil, ocean & $\begin{array}{l}\text { Mixing at } \\
\text { the source }\end{array}$ & $\begin{array}{l}\text { Euclidean } \\
\text { distance }\end{array}$ & - & $\alpha_{0} \bar{\xi}$ & $\frac{\delta(\xi)}{\bar{\xi} k+w}$ \\
\hline
\end{tabular}

See text for the meaning of the symbols.

It is worth mentioning, finally, that these models rely on an assigned field of transporting currents, which is in itself generally derived from a hydrologic, oceanographic or meteorological model, in turn affected by different errors, which can be seldom evaluated. As a conclusion, although in principle much more accurate and capable of detailed description of processes, sophisticated models produce as output spatial distributions of contaminants, which are a priori only one possible (although real-looking and consistent) realization of the environmental dispersion process, unless accurate model calibration is conducted. Model equations cannot be separated by the set of model parameters assigned. The fact that more than one combination of model equations and parameters yield equally satisfactory results, sometimes called model equifinality (e.g. Beven, 2006), further contributes to weakening our belief in even very comprehensive and advanced models.

On the other hand, these models are overwhelmingly data demanding, computation intensive, and require much longer time to run compared to simpler models, which makes them extremely expensive and not practical for routine assessments or preliminary studies. Although modern computers and parallel, high performance computing do not pose, in principle, strong computational limitations, practical constraints when applying numerical solutions of the ADE in environmental modeling still limit their spatial resolution or coverage: as numerical solutions of the ADE are obtained by dividing the computational domain into an array of discrete elements for each of which an equation is solved algebraically, describing a domain of approximately $5000 \mathrm{~km} \times 5000 \mathrm{~km}$ such as continental Europe with a resolution of $1 \mathrm{~km}$ would imply a system of equations of order $2.5 \times 10^{7}$

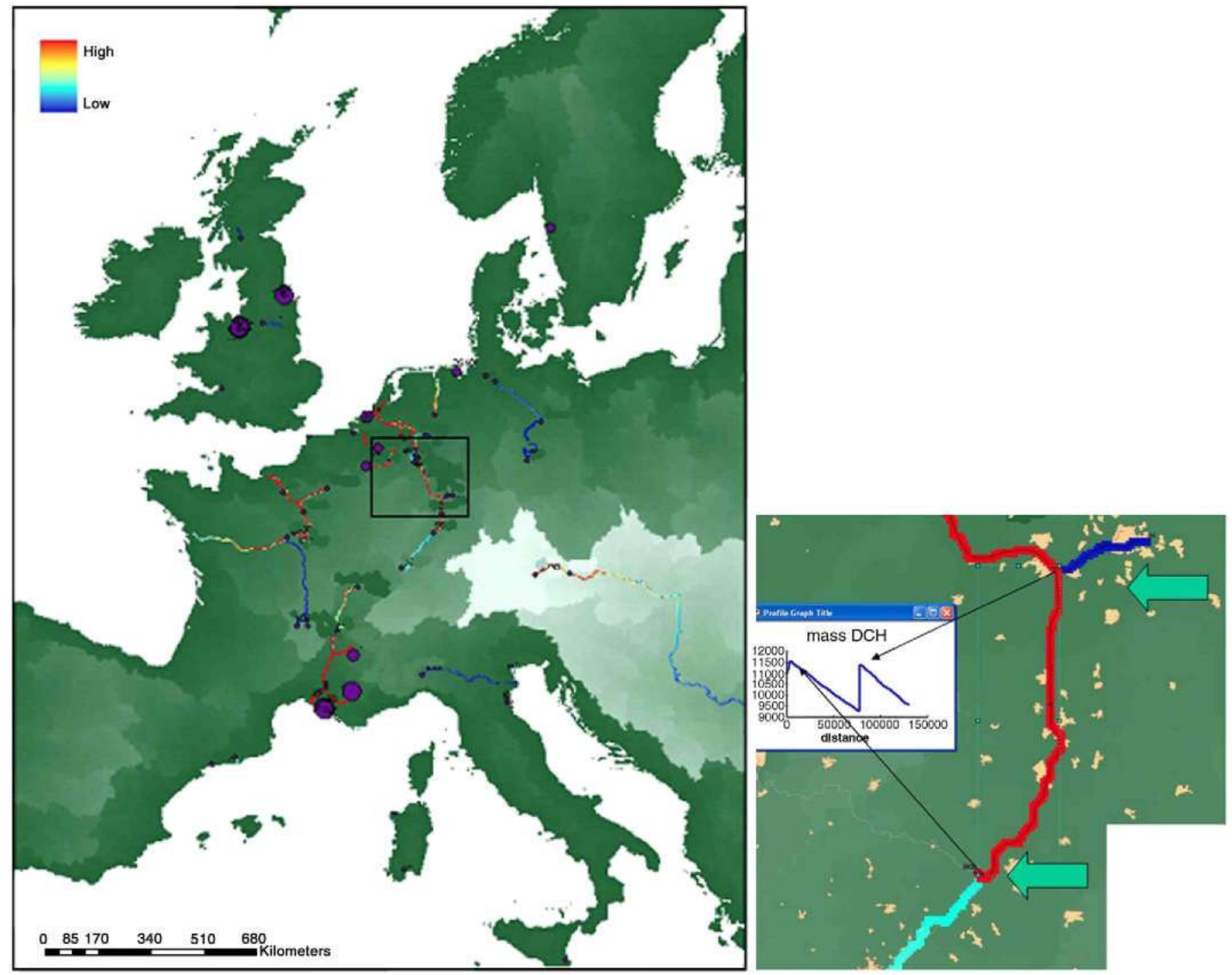

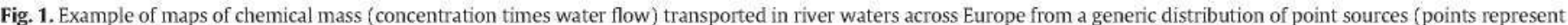

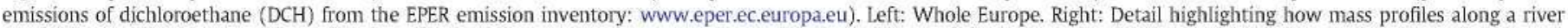

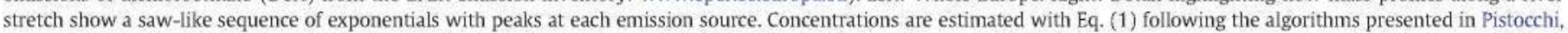
2005. In right panel, arrows represent dichloroethane emissions to water. 

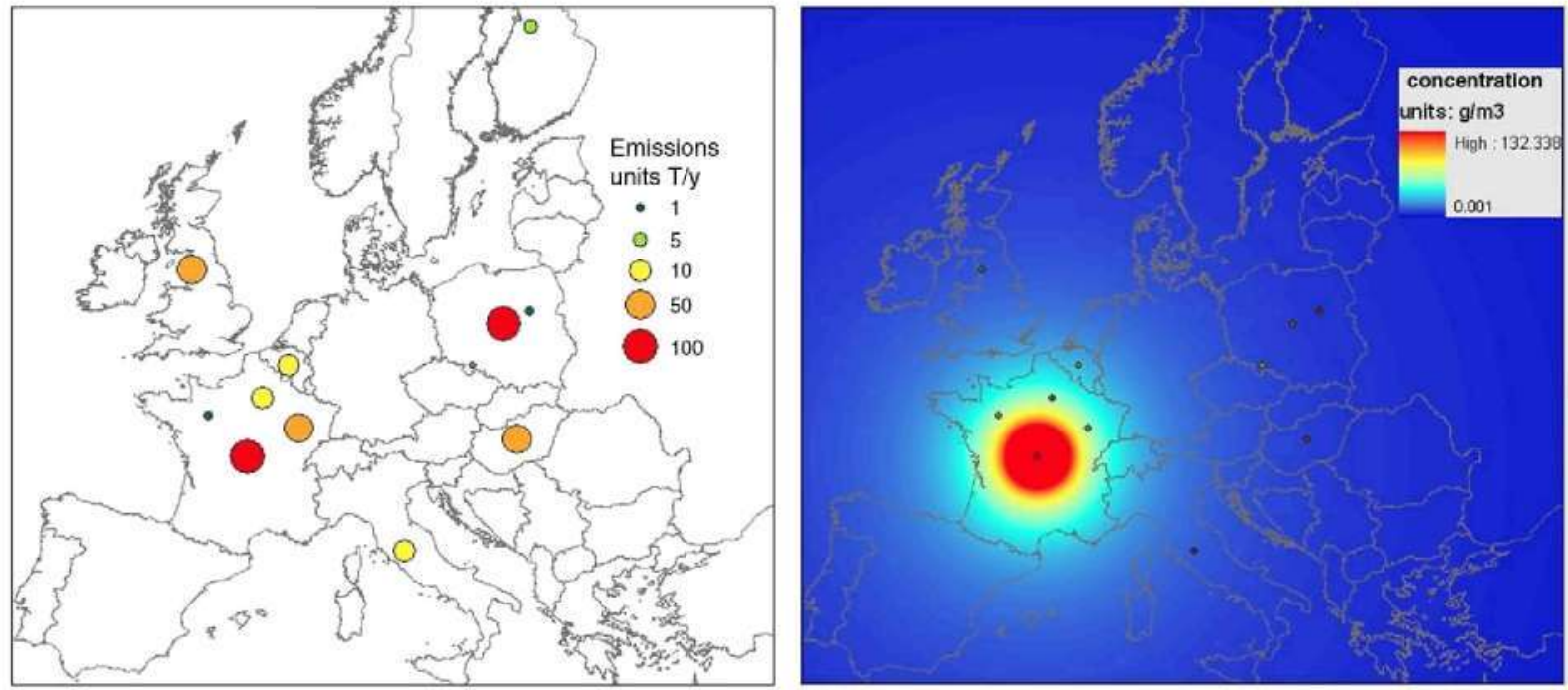

A

B
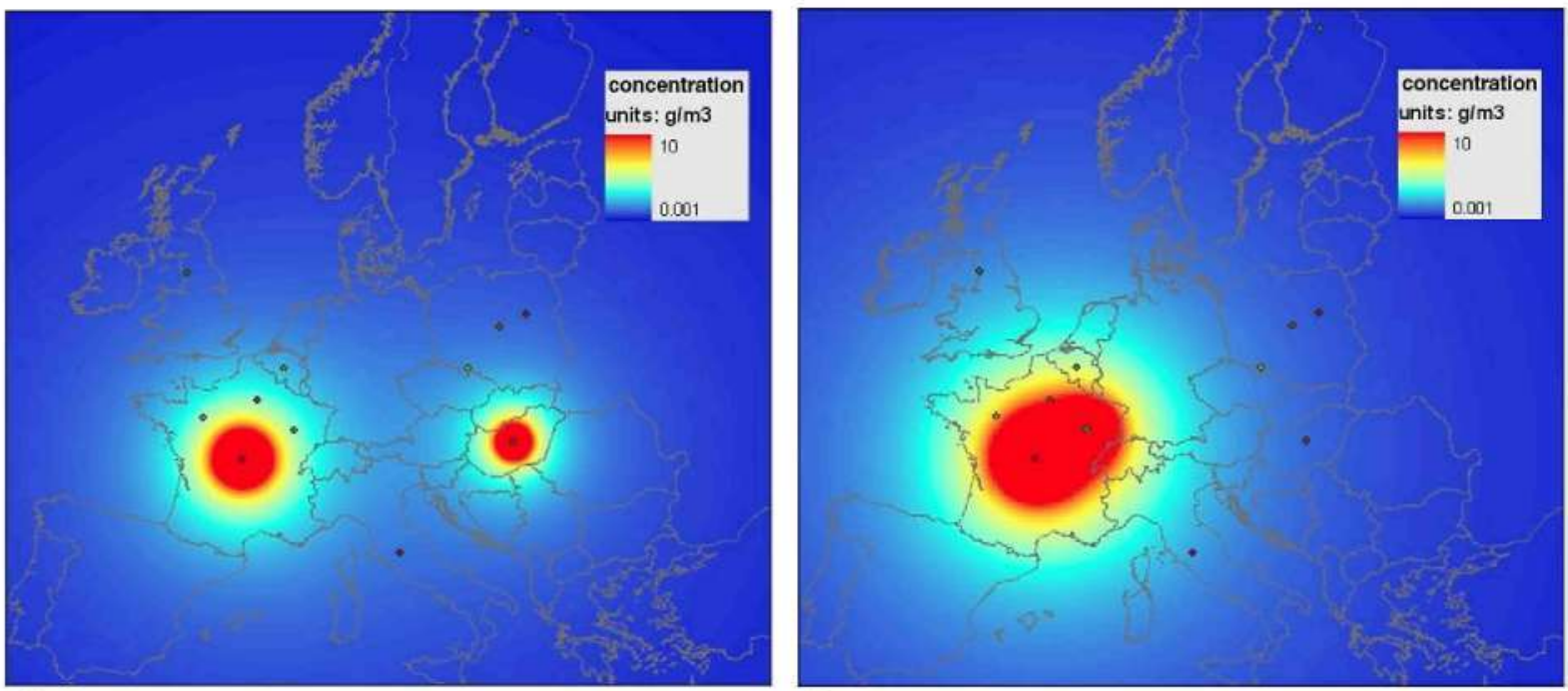

C

D

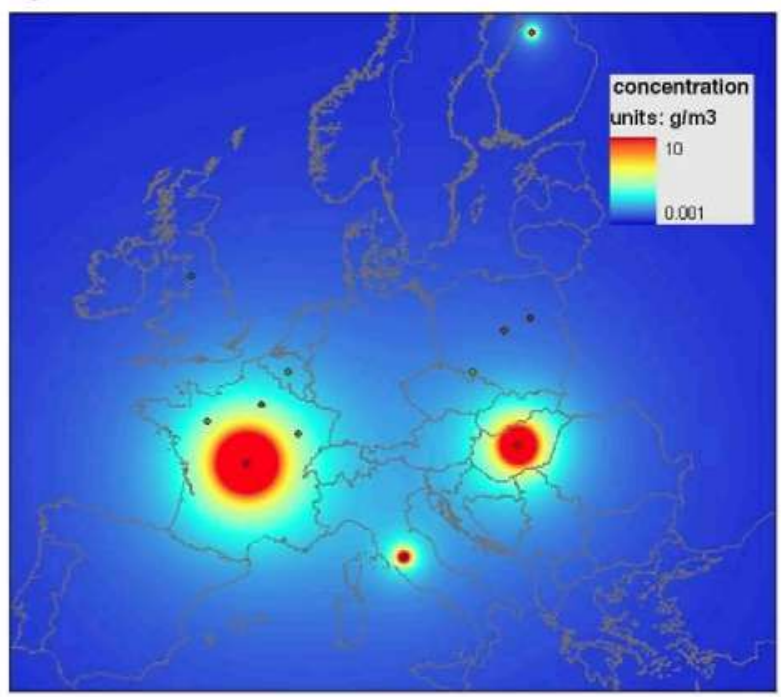

E

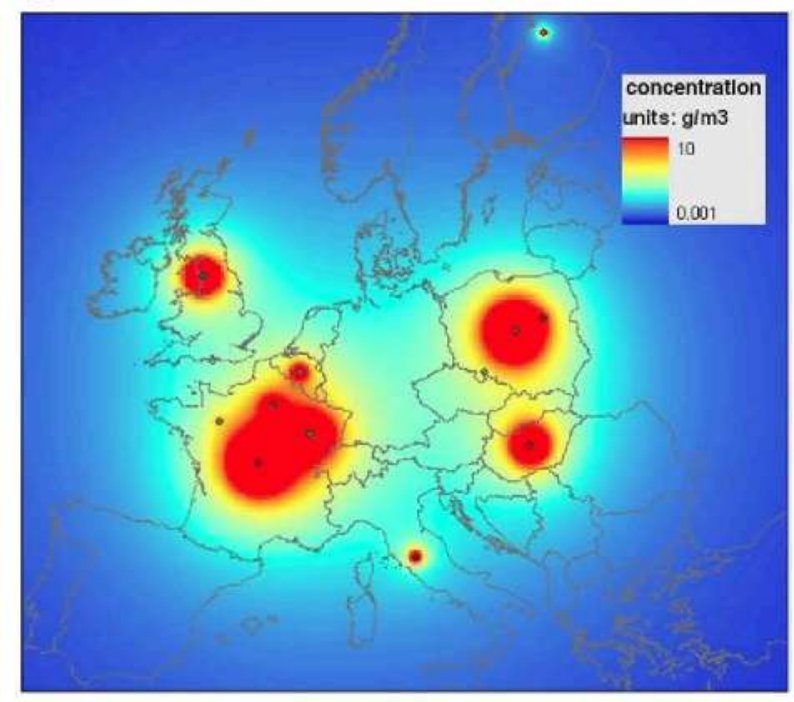

$\mathbf{F}$

Fig. 2. Example of maps of concentrations across Europe of a generic pollutant due to punctual emissions of different intensities, as represented in A. Maps present cumulative concentrations due to emissions in a single point (B), two remote points (C), two close points (D), four distant points (E) and many points distributed across Europe (F). 
Table 2

Examples of landscape and climate parameters used in chemical fate modeling.

\begin{tabular}{|c|c|c|c|c|c|}
\hline Compartment & Parameter & Methods & Examples & Typical resolution & Links \\
\hline \multirow[t]{3}{*}{ Air } & $\begin{array}{l}\text { Atmospheric boundary } \\
\text { layer height }\end{array}$ & $\begin{array}{l}\text { Reanalysis of meteorological } \\
\text { simulations }\end{array}$ & ECMWF ERA40: & $2.5^{\circ}$ & http://www.ecmwf.int/ \\
\hline & $\begin{array}{l}\text { Air temperature, } \\
\text { precipitation, wind } \\
\text { speed }\end{array}$ & $\begin{array}{l}\text { Interpolation of climatological stations; } \\
\text { reanalysis of meteorological } \\
\text { simulations }\end{array}$ & ECMWF ERA40: CRU Climatology & $2.5^{\circ} 10^{\prime}$ & $\begin{array}{l}\text { http://www.cru.uea.ac.uk/ } \\
\text { cru/data/ }\end{array}$ \\
\hline & $\begin{array}{l}\text { Aerosol concentration } \\
\text { and deposition flux }\end{array}$ & $\begin{array}{l}\text { Remote sensing of aerosol optical } \\
\text { depth; specialized atmospheric models }\end{array}$ & $\begin{array}{l}\text { MODIS products; ICAROS products } \\
\text { of LANDSAT TM and SPOT; MERIS } \\
\text { products: TM5, REMSAD. CMAQ } \\
\text { models }\end{array}$ & $30 \mathrm{~m}^{-2} \mathrm{~km}$ & $\begin{array}{l}\text { http://modis.gsfc.nasa.gov/ } \\
\text { http://envisatesa.int/ } \\
\text { instruments/meris/ } \\
\text { http } / / \text { www.plys.uu.nl/ } \\
\text { hn5/ } \\
\text { http://remsad.saintl.com/ } \\
\text { http://www.cmaq-model. } \\
\text { org/ }\end{array}$ \\
\hline
\end{tabular}

\begin{tabular}{|c|c|c|c|c|c|}
\hline & $\begin{array}{l}\text { OH-radical } \\
\text { concentration }\end{array}$ & Specialized atmospheric models & TM5 model (see Pistocchi et al., 2006) & $1^{\circ}$ & \\
\hline \multirow[t]{9}{*}{ Water } & Runoff & Calibrated models & $\begin{array}{l}\text { GRDC composite rumoff fields (Felete } \\
\text { et al., 2000) }\end{array}$ & $30^{\prime}$ & $\begin{array}{l}\text { http:/www.bafg.de/GRDC/ } \\
\text { Home/homepage_node. } \\
\text { html }\end{array}$ \\
\hline & Hydraulic geometry & $\begin{array}{l}\text { Morphological analysis of digital } \\
\text { elevation models (DEM) }\end{array}$ & See Pistocchi and Pennington, 2006 & $\begin{array}{l}\text { Depending on the } \\
\text { digital elevation } \\
\text { model }\end{array}$ & \\
\hline & $\begin{array}{l}\text { Suspended particulate } \\
\text { matter (rivers) }\end{array}$ & $\begin{array}{l}\text { Empirical models, sediment rating } \\
\text { curves }\end{array}$ & See review in Pistocchi, 2008c & $\begin{array}{l}\text { Depending on the } \\
\text { digital elevation } \\
\text { model }\end{array}$ & \\
\hline & $\begin{array}{l}\text { Suspended particulate } \\
\text { matter (seawater) }\end{array}$ & Remote sensing & See Pistoccli et al., 2006 & & $\begin{array}{l}\text { http://oceancolor,gsfc.nasa. } \\
\text { gov/SeaWiFS/ }\end{array}$ \\
\hline & Ocean mixing depth & Models & E.g. GETM model for Europe & & http://getm.eu/ \\
\hline & & $\begin{array}{l}\text { Interpolation of climatological } \\
\text { observations }\end{array}$ & Monterey-Levitus dataset & & $\begin{array}{l}\text { http:/www.cdc.noaa.gov/ } \\
\text { data/gridded/data.nodc. } \\
\text { wod94.htinl }\end{array}$ \\
\hline & Sea temperature & Models & E.g. GETM (See Pistoccli et al., 2006) & $1^{\circ}$ & http://getm.eu/ \\
\hline & & Remote sensing & & & $\begin{array}{l}\text { http://oceancolor.gsfc.nasa. } \\
\text { gov/SeaWiFS/ }\end{array}$ \\
\hline & Sea currents & $\begin{array}{l}\text { Models } \\
\text { Interpolation of drifter data }\end{array}$ & E.g. GETM ( See Pistocthi et al., 2006) & $25 \mathrm{~km}$ & http://getm.eu/ \\
\hline \multirow[t]{3}{*}{ Soil } & $\begin{array}{l}\text { Soil texture, bulk } \\
\text { density, porosity. } \\
\text { olganic carbon }\end{array}$ & $\begin{array}{l}\text { Soil surveys and national/international } \\
\text { compilations }\end{array}$ & European Soil Database & $1 \mathrm{~km}$ & $\begin{array}{l}\text { http://eusoils.jic.ec.europa. } \\
\text { eu/ }\end{array}$ \\
\hline & Soil moisture & Simplified soil water balance models & See Pistocchi et al., 2008 & $1 \mathrm{~km}$ & \\
\hline & Erosion rates & Erosion models & See review in Pistocchi, 2008c & $1 \mathrm{~km}$ & \\
\hline Vegetation & Leaf area index & Remote sensing & $\begin{array}{l}\text { FAPAR derived products; see } \\
\text { Pistocchi et al., } 2006\end{array}$ & $1 \mathrm{~km}$ & http://fapar.jrc.ec.europa.eu \\
\hline
\end{tabular}

But the main disappointment with the use of such models lies often in the excessive detail of their description of chemical fate, compared with the actual knowledge of both chemical emissions and the fundamental physico-chemical properties of substances in the environment. Indeed, predicted environmental concentrations are highly correlated in space to emissions, which may explain a very large portion of the variance (see e.g. the discussion in Hollander et al., this issue). Unfortunately, however, emissions are seldom known in orders of magnitude, and almost never in spatial patterns for most chemicals. Therefore, the use of these models should be limited to detailed studies on pollutants.

\subsection{The issue of model evaluation}

In the literature, there are numerous examples of spatially explicit models used at local or regional scale, with different degrees of success in simulation and prediction. Any review of this material is beyond the scope of this work. It is interesting, on the other hand, to notice that not many models have been fully evaluated for prediction of chemical fate at the continental or global scale. A recent example by Lamon et al. (2009), investigating implications of climate change on the fate of pollutants, shows that the spatially explicit multimedia model BETR Global (Macleod et al., 2005) predicts correct orders of magnitude, and captures general spatial trends, of air concentrations of $\mathrm{PCB}$ congeners 28 and 153 . However, the assessment is referred to 16 measurement points, included in 9 out of 288 cells in the model domain in the Northern Hemisphere. The information used for validation represents the best available knowledge on these chemicals, and gives an idea of the current difficulties in obtaining well-tested model simulations. Given this difficulty of evaluation, it is not surprising that one of the main uses of spatially explicit models is in the development and testing of hypotheses on global transport mechanisms. Examples are provided by the study of the global fate of European PAHs by Sehili and Lammel (2007), using a complex ADE-based transport model; the study of Armitage et al. (2006), on PFOA, using a multiple box model; the assessment of persistence and long range transport potential of chemicals performed by Leip and Lammel (2004), highlighting the importance of exploring global variations in chemical concentration using realistic spatially explicit models. However, studies with similar aims have been conducted also with far simpler models (e.g. Scheringer et al., 2004a,b), and the advantage of using global transport models based on the ADE, with high computational burden and a higher number 

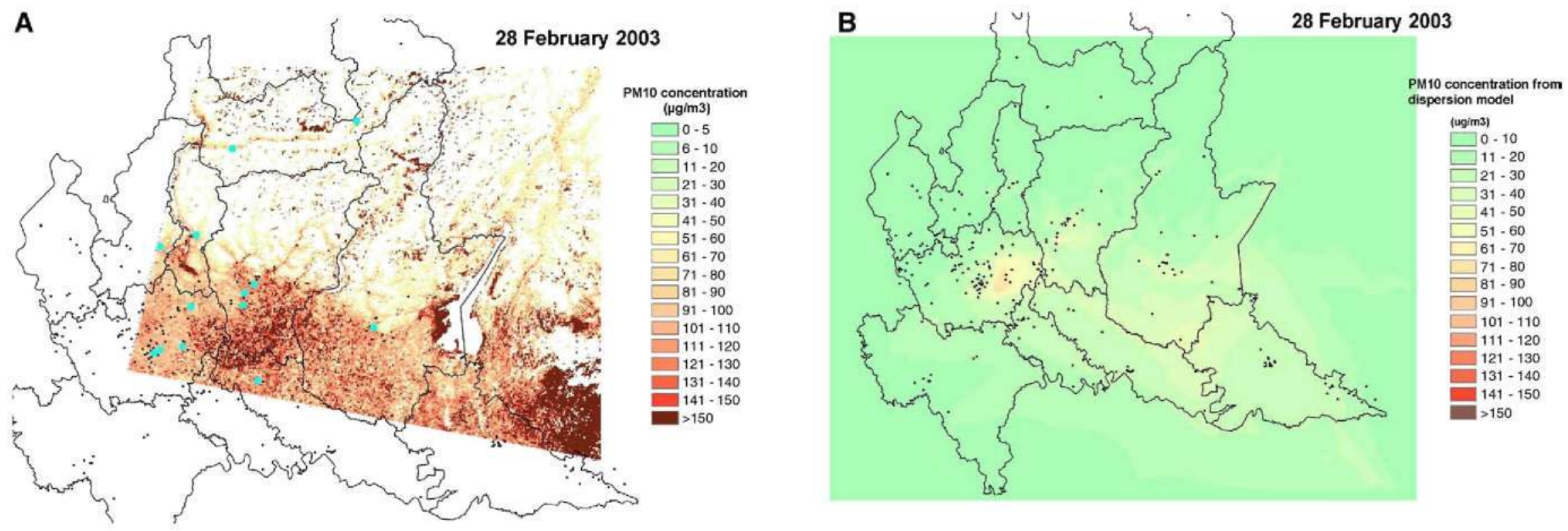

C

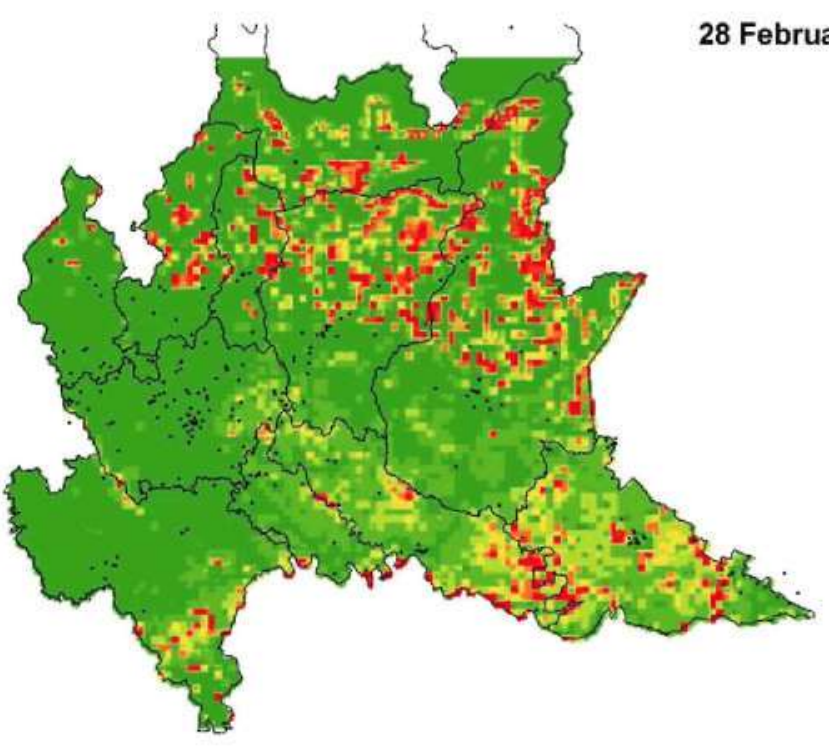

2003

Model weight

$0-0.05$

$0.06 \cdot 0.10$

$0.11 \cdot 0.15$

$0.16-0.20$

$0.21 \cdot 0.25$

$0.26 \cdot 0.30$

$0.31-0.35$

$0.36-0.40$

$0.41 \cdot 0.45$

$0.46 \cdot 0.50$

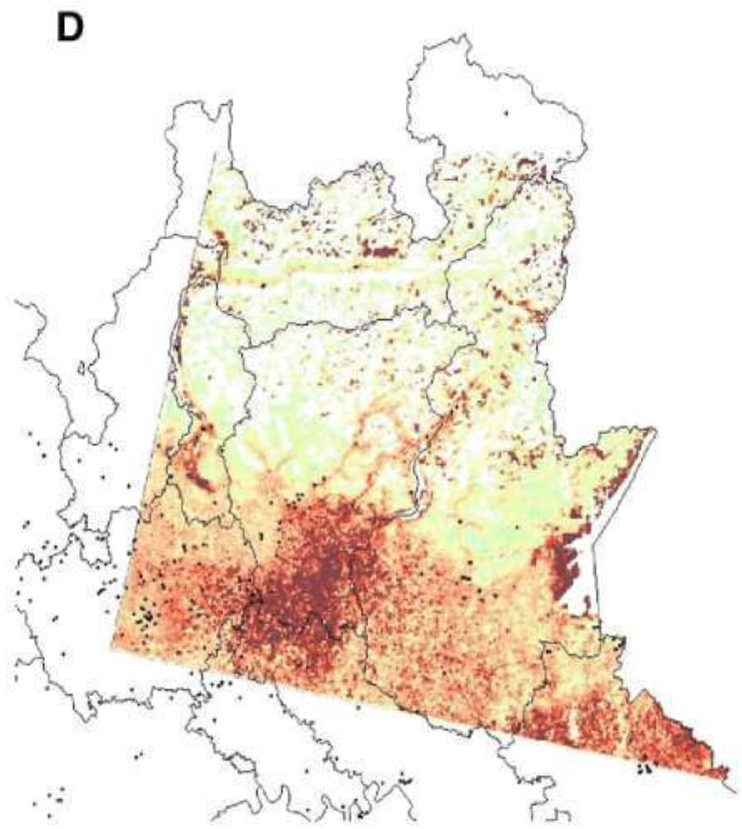

28 February 2003

PM10 concentration

from 2 -nd layer of data fusion (Kalman filter)

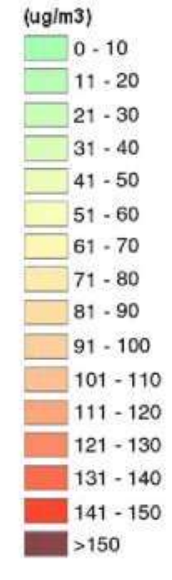

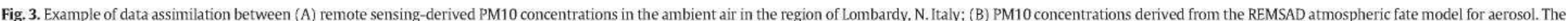
two data models are fused using a Kalman-filter based algorithm that optimizes the assimilation procedure assigning variable weights to the 2 data sources across the domain (C). The final, optimized result is given in map (D). 
of parameters affecting the results (with clear consequences on sensitivity assessment and error tracking) is still to be clearly proven in the absence of full model validation. We will return on the issue of model evaluation later in this paper.

\section{Strategies of simplification}

This practical experience with models has fostered the development of alternative strategies seeking a balance between realism in the spatial distribution of chemicals on one side, and practicity and cost of use on the other. In the literature, there are some examples of models developed in an attempt to simplify the ones based on the ADE, at the same time keeping a relatively very fine spatial resolution. For instance, Bachmann (2006), developed a classic multiple box model with boxes of $1 \mathrm{~km}$ resolution for all processes on land in Europe, while keeping a coarser resolution in the atmosphere, described in tum through a trajectory-based approach. However, the very fine resolution on land does not correspond to knowledge detailed enough, e.g. concerning soil properties or the representation of hydraulic geometries determining water residence times. Moreover, the numerical complexity of calculations does not correspond to the realism in simulation one may expect. given the simplistic first-order representation of many environmental processes. Therefore, this type of approach promises to lead to little improvement with respect to classical multi-box models with coarser resolution, at the same time approaching the computational burdens of ADE-based models.

\subsection{Multimedia models or cascades of media-specific models?}

A first relevant step forward in spatially explicit multimedia chemical fate modeling has come instead from the consideration that, once a chemical is emitted to one environmental compartment, it can be transported to other compartments, but its feedback fluxes from other compartments to the one of emission are very rarely relevant in quantitative terms (Margni et al., 2004). Therefore, for most applications, it is sufficient to treat one compartment at a time (i.e. set up a single-medium chemical fate model), and treat transport to other media as "losses"; then these losses can be used as input to other singlemedium models of different compartments. There are a number of models that can be applied to each single medium, or to a combination of two. Examples of spatially explicit chemical fate models that can be applied to model large regions for different single (or coupled) environmental media include GREAT-ER (Feijtel et al., 1997), a stochastic simulator based on a plug-flow equation model of rivers, that predicts concentrations of chemicals from wastewater and other sources in inland waters and has been used in the context of water management; SWAT (Neitsch et al., 2002), a model including catchment hydrology, soil processes, stream processes, with the resolution of a subcatchment, used for the simulation of nutrients and pesticides over large domains; and LOTOS-EUROS (Schaap et al., 2008), an atmospheric transport model for continental Europe.

A cascade of off-the-shelf single-medium models combined together may be a practical option, but often a single one of these models is in itself already rather complex, and their combination may result in a still very complex model.

\subsection{Meta-models}

An increasingly followed strategy to simplify models is to build meta-models (e.g. Piñeros Garcet et al., 2006). A meta-model can be described as a model that allows estimating chemical concentrations as a function of physico-chemical properties, emission rates and a set of pre-calculated concentration fields corresponding to reference chemicals. Usually such model is obtained through some form of linear or non linear regression analysis (e.g. Tiktak et al., 2006), artificial neural networks (e.g. El Tabach et al., 2007) or other similar techniques. Pre- calculated concentration fields are generated by making emissions and physico-chemical properties vary over appropriate and representative ranges of values, usually following random sampling logics (Piñeros Garcet et al., 2006). An extensive meta-modeling activity has been developed in Europe for pesticides, using the PEARL model (Leistra et al., 2001) within the HAIR project (http://www.rivm.nl/rvs/risbeoor/ Modellen/HAIR.jsp) and the MACRO model (Larsson and Jarvis, 1999) within the FOOTPRINT project (http://www.eu-footprint.org).

Once pre-calculated fields are available, the calculation of concentrations is extremely fast and generally very accurate with respect to the original model. Therefore, meta-modeling is a feasible technique to generalize complex numerical models to cases not yet analyzed. The main problem with this approach is that sometimes the pre-calculation of concentration fields is very time-consuming, and the benefits of precalculation can be observed only when frequent and varied routine application of the underlying model is foreseen. If this is not the case, developing pre-calculated fields may be less convenient than just running the underlying model in different case studies. Moreover, meta-models rely strictly on the underlying model assumptions and parameterization. It is not infrequent that an even well established model undergoes important modifications in time. In such cases, adaptations to the metamodel to reflect modifications simply require re-running the model.

A special case of meta-model is the construction of source-receptor relationships for advective-dispersive media such as the atmosphere or oceans. In such cases, the ADE for a conservative contaminant is always linear. Moreover, in such case the only relevant fate process is, by definition, dilution (advection and dispersion). Roemer et al. (2005), have developed a meta-model that they called ADEPT, which describes the concentration from emissions in each European country, distributed in space like population density, by running the LOTOS model (Builtjes et al., 2003) with appropriate assumptions. Their meta-model takes the form of maps of spatially explicit source-receptor relationships, i.e. concentrations at a given location (receptor) from emission at another (sources). Sourcereceptor model approaches have been extensively adopted in long range atmospheric modeling within global or continental decision support systems such as GAINS (http://gains.iiasa.ac.at/gains/).

\subsection{Analytic elements}

Besides meta-modeling, in recent years attention has been focused on the possibility of describing even irregular, complex patterns using simple fundamental mathematical relationships in place of complex numerical methods. This path has been followed first in the domain of groundwater modeling, where a technique, called of the "analytic elements" (Strack, 1989; Haitjema, 1995), has been developed which consists of a superposition of simple analytical solutions to the ADE, corresponding to individual features such as sources/sinks, discontinuities in flow properties, boundaries, etc. Each solution is infinite in space, and appropriate consistency conditions are specified in order to solve the system of these solutions. In this way, realistic, complex flow patterns can be reproduced by superimposing simple models.

\section{GIS-based modeling}

With the development of computational geography (e.g. Openshaw and Abrahart, 2000) and the proposal of systematizing geographic information system (GIS) practice into a more structured "geographic information science" (Goodchild, 1992), GIS functions have started being studied not just as software functionalities, but rather as "methods" to be used for broad classes of geographic modeling problems. This has fostered the inclusion in GIS of generic operators enabling the construction of simulation models of environmental processes, without the need to code separate numerical models to be eventually coupled with GIS. Examples of this approach, also enabling time-dependent simulation, are provided by the GIS package PCRaster (Van Deursen, 1995; Karssenberg, 2002) which has been also used to 


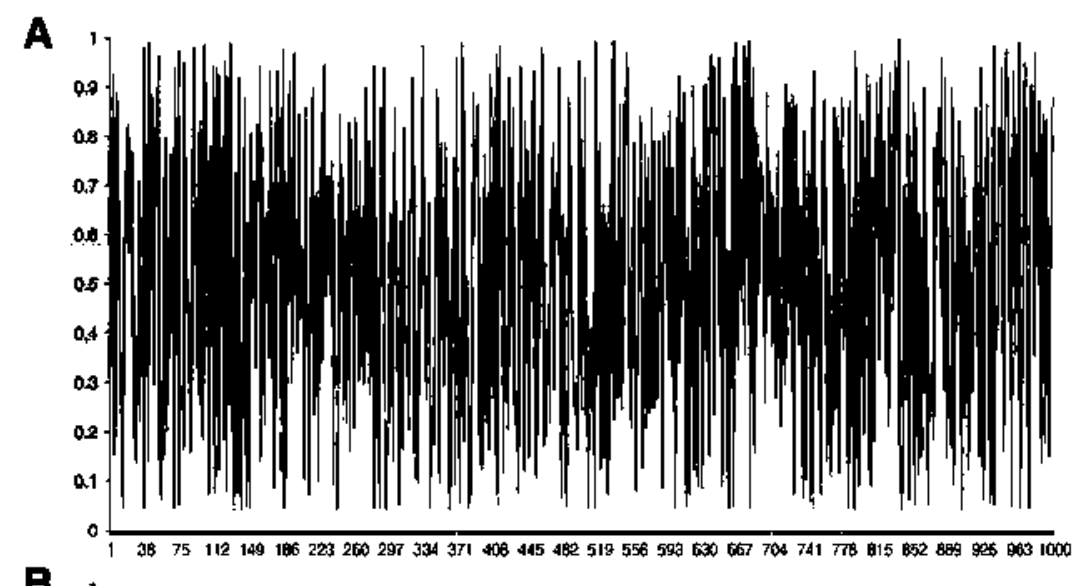

B
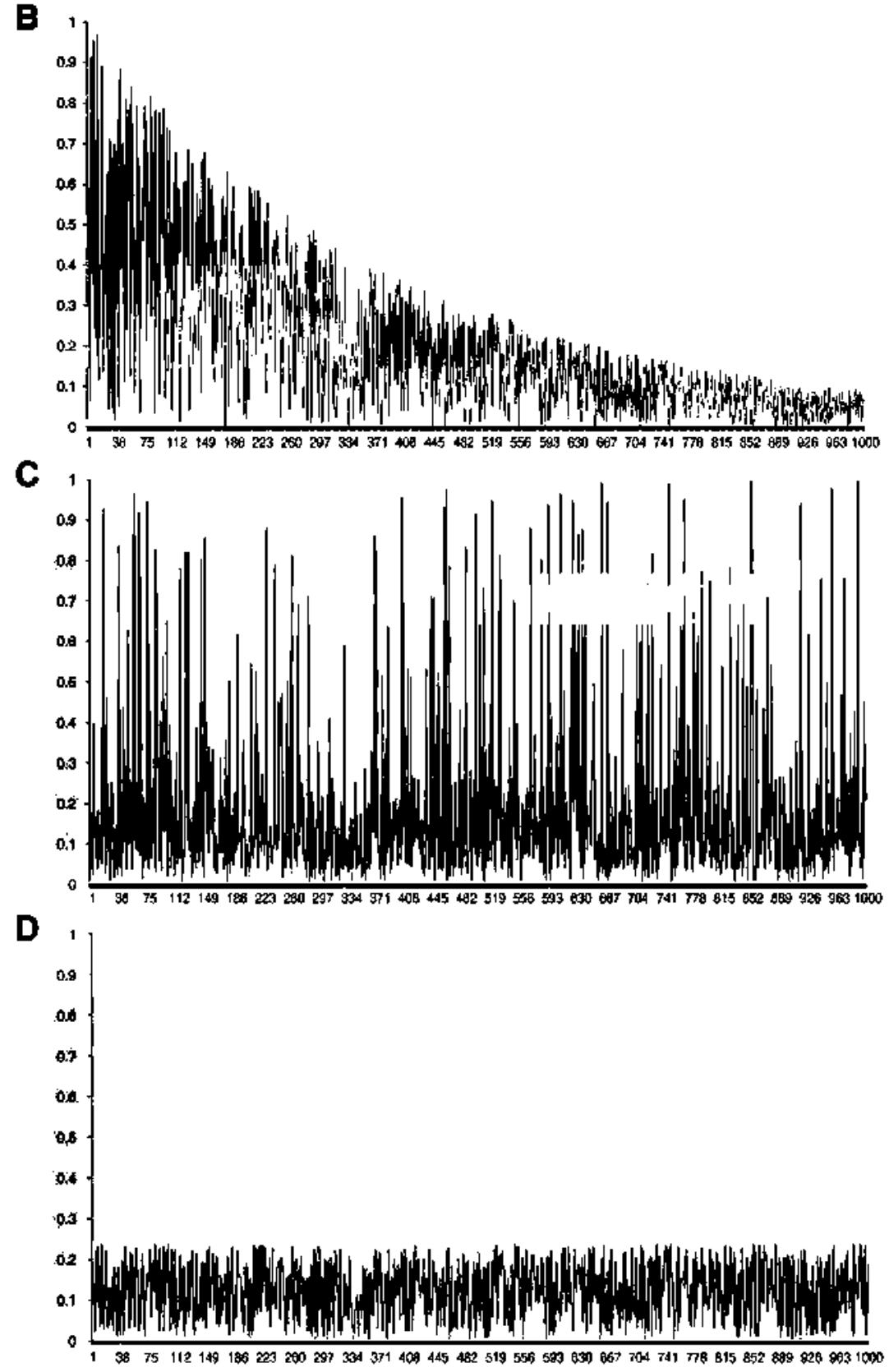

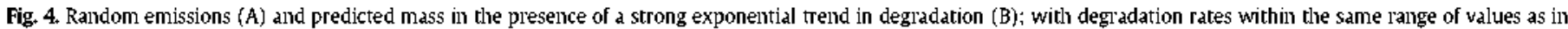

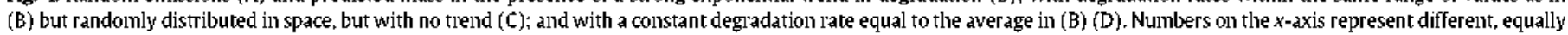
spaced locations along a gradient of temperature. The graplss are merely illustrative. See text for details. 
build a pan-European hydrologic model (De Roo et al., 2000). Another example is the functionality provided by popular ESRI products Arclnfo( and, more recently, ArcGISO, to perform simple groundwater contaminant modeling by combining flow path analysis and timedependent dispersion (see Tauxe, 1994, for further details).

We focus here on an approach, conceptually similar to the analytic elements, proposed in the field of chemical fate modeling, grounding on simple standard GIS-analytical operations, including local drainage delineation and map algebra, to describe the spatial patterns of contaminants (Pistocchi, 2005, 2008b). The basic idea of this approach is to replace the numerical solution to the ADE with a superposition of local analytical solutions: in most cases the spatial distribution of chemicals in the environment can be described as a reasonable first approximation using very simple conceptual schemes, and particularly the elementary flow schemes traditionally applied in compartmental analysis: besides the already mentioned box model, or "continuous stirred tank reactor" (CSTR), the plug-flow (PF) and Gaussian plume (GP) models usually represent well most of the typical environmental distributions.

\subsection{The plug-flow model}

For instance, a PF model is often the elective tool for simulation of river quality (e.g. Chapra, 1997). In this case, concentration of a chemical substance along the stream network downstream of an emission of intensity $E$ is described by the analytical solution:

$C(\xi)=\frac{E}{\alpha(\xi) w} e^{-\frac{k \xi}{w}}$

where $w$ is the stream velocity, $x$ the curvilinear abscissa along the stream line $\Gamma$ originating from the emission point, with origin $\xi=0$ at the location of emission, $\alpha(\xi)$ is the stream cross sectional area (which can be represented as in Pistocchi and Pennington, 2006), and $k$ is the first-order decay constant of the chemical.

When $w$ and/or $k$ are not constant but depend on $\xi$, the exponential in Eq. (1) needs to be replaced by $e^{-\int_{0}^{k} \frac{k}{n} d \xi}$. The formula can be computed practically as explained by Pistocchi (2005). The curvilinear abscissa $\xi$ can always be converted to geographic coordinates $(x y)$ given the position of the stream network.

\subsection{The Gaussian plume model}

The GP model is used for screening level modeling of air emissions (e.g. Turner, 1994), groundwater pollution (e.g. Domenico and Schwarz, 1998), and ocean or lake dispersion problems (Csanady, 1973). In this case, concentration downstream or downwind of an emission, within a field of wind or water current of constant intensity $w$ and direction parallel to the $p$-axis, is:

$C(p, q)=\frac{E e^{-\left(\frac{q}{a p^{b}}\right)^{2}}}{\alpha_{0} w\left(a p^{b}\right)} e^{-k \frac{p}{w}}$

$\alpha_{0}$ is a parameter representing dilution near the source and is conceptually similar to a mixing depth/height, as discussed in Pistocchi and Galmarini (in press), while $a$ and $b$ represent empirical parameters of plume dispersion. It is clear that the Gaussian plume scheme cannot be used when variations in wind or current direction and intensity are relevant, as in the case of continental scale modeling. However, with reference to atmospheric dispersion in the European context, it has been shown that Eq. (2) can be replaced with the following:

$C(p, q)=\frac{E}{\alpha_{0} w \xi^{b}} e^{-k_{n}^{\frac{E}{n}}}$ with $\xi=\left(p^{2}+q^{2}\right)^{0.5}$, which proves valid over long distances, irrespective of wind, $w$ (Pistocchi and Galmarini, in press). Also, those authors suggest acceptable values of parameters $\alpha_{0}, b$ and $w$ generally applicable in Europe for screening level modeling.

\subsection{The continuous stirred tank reactor}

For the CSTR model, concentration is:

$C(p, q)=\frac{E}{\alpha_{0} \bar{\xi}}\left[\frac{\delta(\xi)}{\bar{\xi} k+\bar{w}}\right]$

where $\bar{\xi}$ is the side length of the CSTR, $\alpha_{0}$ represents the mixing height or depth of the CSTR, $\bar{w}$ is the average wind or water current speed within the CSTR, and $\delta(\xi)$ is the integral of the Dirac delta function over the CSTR, equal to 1 for $\xi \leq \xi$ and 0 for $\xi>\bar{\xi}$. Eq. (3) can be used only to predict the concentration at the emission location, but not outside of it. This scheme can then be used when dilution outside of the emission location is so high that concentrations become negligible, as is the case of small emissions to the ocean compartment, or when $k$ dominates over $\alpha_{0} w$, i.e. advection is negligible.

\subsection{Generalization for GIS-based modeling}

Using these simple flow schemes allows the prediction of the local pattern of concentration by assuming a priori the mathematical shape of the patterns of concentration arising from a given source. The three simple models of Eqs. (1), (2') and (3) can be used to compute concentrations everywhere in space arising from a single emission at a given location. Their characteristic is that they are just algebraic combinations of functions of spatially distributed parameters and an appropriate distance from emissions, in the form:

$C=\frac{E}{D} R$

where $E$ is the emission value, and $D$ and $R$ are maps representing the "dilution function" $D$ and the "removal function" $R$, and can be represented as maps as a function of an appropriate distance $\xi$ from the source of emission. Table 1 summarizes the meaning of terms $R, D$ and the type of distance $\xi$ to be used in Eq. (4) for the cases discussed above.

For a spatial distribution of emissions, the linearity of the ADE considered here allows to simply superimpose the results from the different emissions. The most trivial case is for Eq. (3); in this case, one may consider a map of emissions $E$ and maps of $k, \alpha_{0}$ and $\bar{w}$ values, and the overall results is just the algebraic combination of these maps. For the case of Eq. (1), it is possible to use specific superimposition functions known as "flow accumulation" (Burrough and McDonnell, 1998; Pistocchi, 2005). An example of this type of calculation is shown in Fig. 1. For Eq. $\left(2^{\prime}\right)$, one calculation for each emission location is required, and then results for all emission points need to be summed together. This may become very impractical for a large number of emissions, but it is still very convenient for a limited number of sources (of the order of $10^{3}$ ), compared with running complex numerical models (Vizcaino and Pistocchi, in preparation). An example of this calculation is shown in Fig. 2. Calculations conducted in this way are usually much quicker than the corresponding numerical models. Also, the model resolution is not as strongly limiting as in the case of numerical methods, because it is not related to the order of a system of equations to be solved, as in the case of models based on the ADE.

The use of these simplified models, implemented directly using GIS-analytical capabilities, allows obtaining reasonably realistic spatial distributions of chemical concentrations, through extremely simple calculations. This has been shown with reference to the 

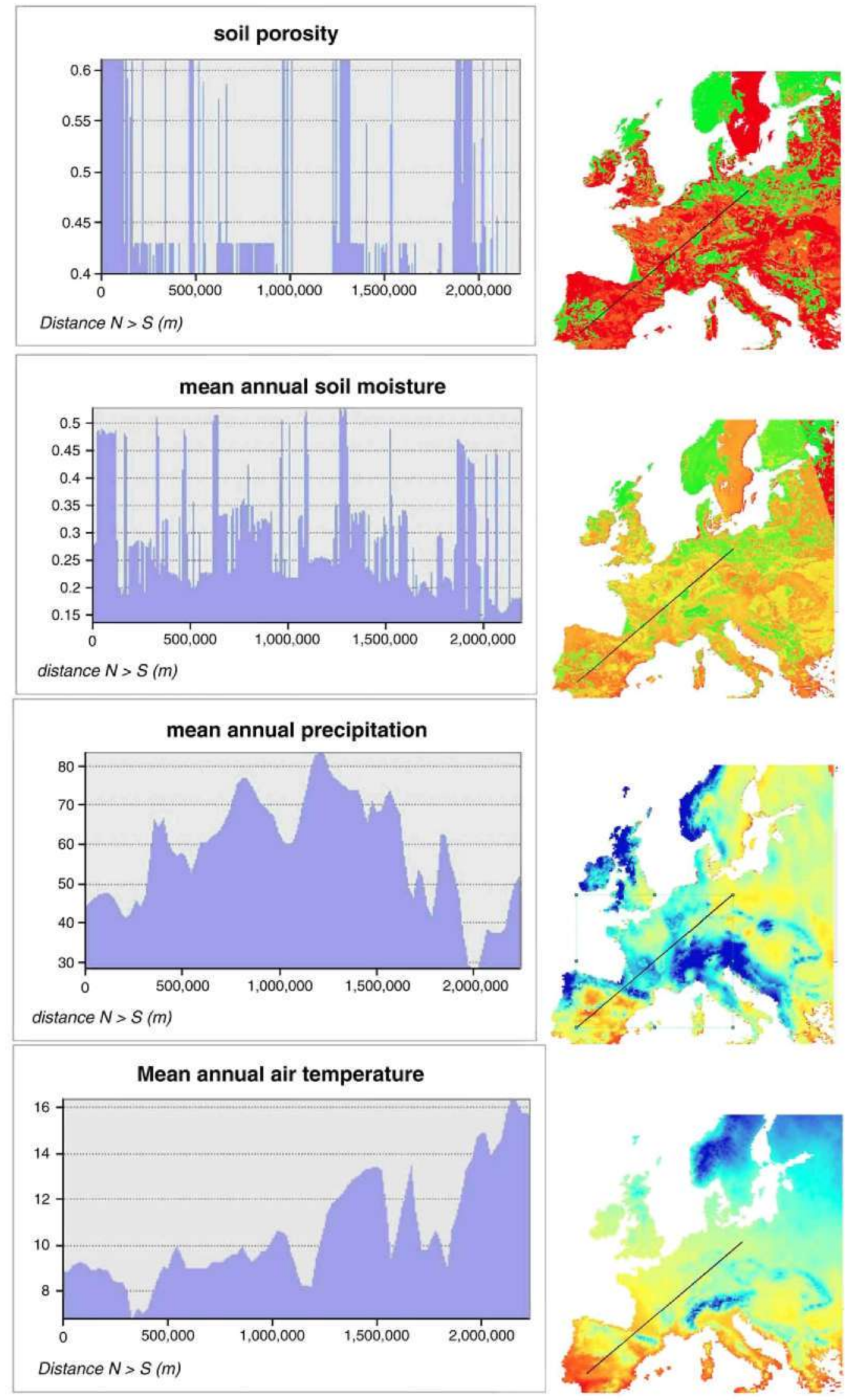

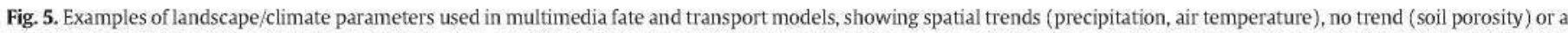

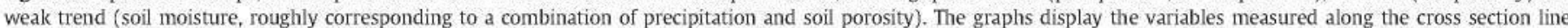

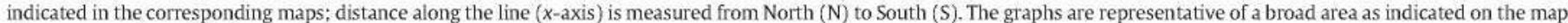
of mean annual precipitation. 
continental distribution of PCBs and dioxins in Europe (Pistocchi, $2008 \mathrm{~b}$ ): to the fate of pyrethroid insecticides in Europe (Pistocchi et al., 2009); to the distribution of lindane in Europe (Vizcaino et al., in preparation); and industrial emissions from the European Pollution Emission Register (EPER) (Pistocchi and Galmarini, in press).

\section{Relevant landscape and climate parameters for spatially explicit chemical fate models}

\subsection{Data availability on the Digital Earth}

An aspect of utmost importance in the use of spatially explicit chemical fate models is the choice of landscape and climate parameters. There is now an unprecedented availability of spatial information covering the whole globe, and more in detail specific regions such as the US or, more recently, Europe. In the years from the first theoretical discussions on the "Digital Earth" concept (Wikipedia, not dated) in the early 1990s, to the implementation of Google Earth and similar tools in mid 2000 s, all human activities, and particularly scientific investigation, have seen their geographic dimension enormously empowered and made explicit. In Europe, the adoption of a directive on an infrastructure for spatial information (EC of the Directive, 2007) promises to consolidate a scenario where landscape and climate parameters no longer represent a problem for fate and transport modeling; similar conditions occur in other parts of the world. Fate and transport models require a potentially endless list of landscape and climate variables, of which the most common are summarized in Table 2. It is not uncommon that new mechanisms, and consequently new environmental parameters required for their representation, come to the attention of researchers. For instance:

- In recent times, studies on the effects of intermittent rainfall have suggested the utility of the number of dry days per month as a proxy in fate and transport modeling (Jolliet and Hauschild, 2005);

- The importance of sinking fluxes associated with organic matter has suggested the use of chlorophyll in seawater (Dachs et al., 2002): and

- Studies on the sorption of chemicals to suspended matter in air or water support the adoption of more complex parameterization of these variables (Götz et al., 2007).

A relevant impulse to the development of spatial data sets has been given by increasingly available remote sensing products, more and more used also in the field of chemical fate modeling (e.g. vijayaghavan et al., 2008; Jurado et al., 2004; Montzka et al., 2008; Boschetti et al., 2006).

\subsection{Data assimilation}

In particular, data assimilation techniques bringing together remote sensing datasets with deterministic modeling results bear great potential for improving further the realism of environmental characterization provided by the respective models. This can be of particular importance when assessing the link between environmental pressure and human health risk (Sarigiannis et al., 2002, 2004). A good example of the usefulness of data assimilation in this regard is given by the study of particulate matter pollution in the ambient air at the regional scale. At this scale several problems with the spatial and temporal coverage of the environmental monitoring networks hamper the efficacy of pollution pattern determination. Lack of accuracy in key input parameters, including emission inventories, constrain the applicability of complex atmospheric models. Assimilation of particulate matter data from ground-based measurements with optical indicators of pollution such as turbidity as measured by the optical depth of atmospheric aerosol can enhance both the spatial extent and validity of the air pollution data in a spatially resolved manner. This allows the generation of a model for translating optical indices into pollutant concentrations with the aid of ancillary models and data sets such as meteorological and landscape information (Fig. 3(A)). Further fusion of this model with results from deterministic atmospheric fate modeling using decision-theory based algorithms to optimize the assimilation of the underlying data on the basis of self-estimates of uncertainty (e.g. using the well known Kalman filter) results in a meta-modeling system, which optimizes the uncertainty profiles across the computational domain (Fig. 3(B)). The model fusion algorithm assigns automatically variable weights to the different data sources (e.g. the atmospheric fate models, see Fig. 3(C)) depending on the determination of the minimal residual error of the method across the computational domain. The final result is an improved map of the horizontal profile of PM10 concentrations, characterized by optimal use of all relevant datasets and models (Fig. 3(D)).

\subsection{Types of variability in landscape and climate data, and their relevance in spatial predictions}

It should be stressed that the required detail in the description of the environment depends on the purpose of modeling. Some parameters are intrinsically so highly variable, that an explicit account of their spatial distribution increases the variability of predicted chemical concentrations, but does not provide any better insight on the spatial trends, hot spots etc., which are dominated by the interplay between emissions and environmental parameters. As an example, let's consider the case of a random emission to soil at a number of locations (Fig. 4(A)), for a chemical subject to degradation only (i.e., all other removal mechanisms are negligible). Let's also assume that degradation follows a strong exponential trend with temperature, increasing with location number. The distribution of predicted mass, i.e. ratio of emission to degradation rate, will follow an exponential decrease consistent with the trend in degradation (Fig. $4(\mathrm{~B})$ ). The oscillations of mass across the trend depend on the variability of emissions. Let's now assume that degradation rates are distributed randomly, following a Gaussian distribution with the same mean and standard deviation as the temperature-dependent rates. We have then a distribution of predicted masses as in Fig. 4(C). If we eventually replace the random-varying rate of Fig. $4(\mathrm{C})$ with the average of removal rates, we obtain the distribution of predicted masses of Fig. 4(D). In Fig. 4(C), inclusion of the spatial variability of the degradation rate increases significantly the variability of mass, but does not allow detecting trends. Therefore, it is appropriate to include the variability of the degradation rate if one is interested in extremes, but not if one wants to highlight hotspots or geographical trends.

In reality, the different parameters used in models may or may not show a spatial trend. Fig. 5 shows examples of such parameters, which appear to have different evidence of spatial trends. An objective way to detect spatial trend, as is well known, is to draw the variogram of a spatially distributed variable, i.e. the plot of the variance of data points at a given spatial distance, as a function of the distance itself (see e.g. Clark, 1979), as is common practice in the geostatistical analysis of data.

\section{The evaluation of spatially explicit models}

An issue of key importance in any modeling exercise is the evaluation of models with observations. In the specific case of spatially explicit fate models of chemicals, evaluation poses a number of issues. First of all, chemicals are typically measured in the environment at trace levels, the collection of sufficiently representative samples may be extremely difficult and, sometimes, analytical procedures are not sufficiently consolidated, and do not provide sufficient quality assurance (e.g. Lepom et al., 2009; Quevauviller et al., 2007).

Even when good sampling and analytical procedures exist, the costs of sample collection and analysis often make data generally rather rare and sparse; especially for substances of high variability in time and space, it is extremely difficult to build a data set of samples 
well representing the "true" spatial distribution. More often, samples only reflect the statistics of environmental concentrations, and not values that can be considered stable point-wise, hence used for the point-wise assessment of models. For this purpose, only observational data should be used that were originally conceived and developed as "spatial"; these data are increasingly available for large regions or the globe, e.g. from monitoring of lipids from commercial milk products (Kalantzi et al., 2001; Weiss et al., 2005; Malisch and Dilara, 2007), air passive samplers (Gioia et al., 2007; Jaward et al., 2004), and systematic spatial sampling of a given environmental medium (Mejier et al., 2003; Loos et al., 2009).

For these reasons, with spatial predictions we do not necessarily seek to match monitoring data to an extreme accuracy: modeling exercises have been judged successful or useful even when highlighting orders-of-magnitude discrepancies with observations; models may happen to be considered acceptable when matching orders of magnitude with no or weak correlation with observations in space, and such correlation has been demonstrated to be sufficiently high only in a few cases. When selecting the level of computational complexity of fate models, the fact that model evaluation is at least troublesome and sometimes impossible with the given data available cannot be ignored. Therefore, on the one hand using comprehensive models describing detailed mechanisms of transport in the environment may be useful in order to provide a benchmark; on the other hand, considering that no model represents the truth and even highly physics-based models introduce at some point semi-empirical parameterizations and arbitrary assumptions, complex models may tend to lack transparency and hide some of their assumptions behind their own complexity, thus making the tracking of model errors a difficult task: moreover, their realistic-looking output based on great computational capabilities tends to define a virtual reality obeying the rules included in the model, and thus pushing simpler models to mimic their output rather than observations, in turn scarce and difficult to retrieve. This basically obliterates the lines of research not included in the development of the complex models used as benchmark.

\section{Conclusions and perspectives: GIS-supported revival of simple models?}

\subsection{Models and observations in hypothesis testing}

In the last decades, voices have been raised against the development of overly complex models, especially in such fields as hydrology, where terrific computational developments have eventually shown that little further progress can come from modeling, and relevant steps forward are necessarily related to developments in measurement techniques (e.g. Beven, 2001). On the contrary, a very strong movement has grown in parallel, aimed at fostering the use of models as tools for hypothesis testing rather than accurate simulators of reality (e.g. Beven, 2006). This has brought researchers and practitioners to reconsider simple models not just as remainders from the times when computation was expensive, but rather as parsimonious ways to interpret the complex reality in the presence of limited experimental information, hence preferable according to the Ockham's razor principle. The same considerations apply to chemical fate assessment, an area where hardly any further development is expected on the computational side, if not paralleled by substantial advances on observations.

\subsection{The crucial role of chemical emission maps}

Current limitations in the development of chemical fate models are identified mainly in the lack of information on chemical emissions to the environment; therefore, developing complex and computationintensive models, which involve a high effort in development, is likely to bring no better results than much simpler calculations that can be crudely summarized as estimates of chemical masses by algebraic combination of maps of emissions and dilution or removal factors (Eq. (4)). This is true in general, but particularly so for spatially explicit models, where emissions explain usually a very large amount of the variance in environmental concentrations of a given chemical. In this case, the most critical piece of information, and the most relevant area of research, seems to be about emission inventorying (e.g. Pistocchi and Bidoglio, in preparation; Hollander et al., in preparation; Pistocchi and Loos, 2009).

\subsection{Way forward: maps and simple calculations for hypothesis testing}

In this paper, we have discussed a few aspects related to the development and use of spatially explicit models for the prediction of chemical fate at the scale of the European continent and similarly large regions. A shift in model use from process simulation to hypothesis testing is under progress, in which explaining the discrepancies between observed and computed chemical concentrations in the environment takes importance over prediction per se.

This shift may take advantage of using simple models with residual uses of complex models for detailed studies, under conditions of high uncertainty concerning emissions and environmental processes such as phase partitioning and degradation. In addition, GIS technology and methods invite to developing models by reasoning in terms of maps, keeping the model structure extremely simple (as to be implemented with map algebra) and capitalize on spatial data to refine the spatial representation of environmental drivers such as landscape and climate variables, and better emission estimates.

The problem, in this perspective, becomes one of producing appropriate maps of emissions, on the one hand, and removal rates, on the other hand; the latter capitalize on available spatial data sets of landscape and climate parameters such as air temperature, vegetation, precipitation, soil organic carbon content, runoff, etc., which are increasingly available for large regions also as a consequence of developments in remote sensing of the earth system. Such simple calculations based on a wealth of spatial information on environmental variables maintain an ease of tracking errors, visualizing intermediate results and discussing in a quick and productive way the orders of magnitude of phenomena of which the interplay results in the environmental concentration of chemicals. At the same time, this approach lends itself to reducing the егror of the overall environmental fate assessment across the spatial domain of study. This can be achieved by the application of model fusion techniques employing decision-theory approaches and information filters (such as the Kalman filter) to optimize the relative importance of different superimposed modeling results on the basis of a weight-of-evidence approach. This approach, which so far has been successfully implemented in atmospheric pollution problems for integrating satellite-based remote sensing with atmospheric models and ground-based air quality monitoring data, could be a viable advancement towards the enhanced utilization of GIS-based environmental fate models at the continental and regional scale.

It can be stated, in summary, that the problem is not "how to compute" (given the wealth of available numerical methods, spatial/temporal model ressolution, quantitative uncertainty and sensitivity analysis techniques. etc.) but "what to compute", as often our knowledge of emissions and environmental processes, and our chemical monitoring systems limit the application of even very simple models.

\section{Acknowledgements}

The work presented here has been partly funded by the European Commission FPG contract no. 003956 (NoMiracle IP: http://nomiracle.jrc. ec.europa.eu). 


\section{References}

Almitage J, Cousins IT, Buck RC, Russell MH, MacLeod M, Korzeniowski SH. Modeling global-scale fate and transport of perfluorooctanoate emitted from direct sources. Environ Sci Technol 2006;40:6969-75.

Annitage James $M$, Cousins lan T, Hauck Mara, Harbers Jasper V, Huijbregts Mark A] Empirical evaluation of spatial and non-spatial European-scale multimedia fate models: results and implications for chemical risk assessment. J Environ Monit 2007:9:572-81

Bachmann T. Hazardous substances and human health: exposure. Elsevier, Amsterdam: Impact and External Cost assessment at the European Scale; 2006.

Beven KJ. A discussion of distributed lydrological modelling. In: Abbott MB, Refsgadrd IC, editors. Distributed hydrological modelling. The Netherlands: Kluwer Academic Publishers: 1996. p. $255-78$.

Beven $\mathrm{K}$. Revisiting the problem of model choice, in "rainfall-lunoff modeling: the primer". Chichester: Wiley: 2001. $361 \mathrm{pp}$

Beven K. A manifesto for the equifinality thesis. J Hydrol 2006;320:18-36.

Boschetti M, Brivio PA, Carnesale D, DiGuardo A. The contribution of lyyperspectral remote sensing to identify vegetation characteristics necessary to assess the fate of persistent organic pollutants (POPs) in the environment. Ann Geophys 2006;49(1):177-86.

Brandes LJ den Hollander $\mathrm{H}$, van de Meent D. Simplebox 2.0: a nested multimedia fate model for evaluating the environmental fate of chemicals. RIVM Report no. 719101029, Bilthoven; 1996. [December|.

Builtjes PJH, van Loon $M$, Schaap M, Teeuwisse S, Visschedijnk AJH, Bloos JP. Project on the modelling and verification of ozone reduction strategies: connribution of TNOMEP. TNO-report, MEP-R2003/166, Apeldoorn, The Netherlands; 2003.

Burrough PA, McDonnell R. Principles of GIS. II ed. London: Oxford University Press; $1998.333 \mathrm{pp}$.

Chapra S. Surface water-quality modeling. New York: MoGraw-Hill Int Ed; 1997. 844 pp.

Clark I. Practical geostatistics. London: Applied Science Publishels Ltd; 1979.129 pp.

Csanady GT. Turbulent diffusion in the enviromment. Dordreclit: Reidel Publishing Company: 1973.248 pp.

Dachs J. Lohmann R, Ockenden W. Mejanelle L, Eisenreich SJ. Jones KC. Oceanic biogeochemical controls on global dynamics of POPs. Environ Sci Technol 2002;36:4229-37.

De Roo APJ, Wesseling CG, Van Deursen WPA. Plysically based river basin modelling within a GIS: the LISFLOOD model. Hydrol Process 2000: 14(11-12): 1981-92.

Directive 2007/2/EC of the Directive of 14 March 2007 establishing an Infrastructure for Spatial Information in the European Community (INSPIRE).

Domenico PA, Schwarz FW. Physical and chemical hydrogeology. Wiley0-471-59762-7; $1998.506 \mathrm{pp}$.

EC, 2003. Technical Guidance Document in support of Commission Directive 93/67/EEC on Risk Assessinent for new notified substances, Commission Regulation (EC) No 1488/94 on Risk Assessment for existing substances and Directive $98 / 8 / \mathrm{EC}$ of the European Parliament and of the Council concerning the placing of biocidal products on the market. (http://ecb.jrc.it).

EC, 2004, European Union System for the Evaluation of Substances 2.0 (EUSES 2.0). Prepared for the European Chemicals Bureau by the National Institute of Public Health and the Environment (RIVM), Bilthoven, The Netherlands (RIVM Report no. 01900005). Available via the European Chemicals Bureau, http://ecb.jrc.it.

El Tabach E. Lancelot Laurent, Shahrour Isam, Najjar Yacoub. Use of artificial neural network simulation metamodelling to assess groundwater contamination in a road ploject. Math Comput Model 2007:45(7-8):766-76 |April].

Feijtel TCJ. Boeije G, Mattlies M. Young A. Moris G, Gandolfi C, et al. Development of a geography-referenced regional exposure assessment tool for European riversGREAT-ER. Cliemospliere 1997;34:2351-73.

Fekete BM, Vörösmarty Cl, Grabs W. Global composite runoff fields based on observed river discharge and simulated water balances. Global Rumoff Data Center report no 22; 2000 .

Gioia R, Sweetman AJ, lones KC. Coupling passive air sampling with emission estimates and clremical fate modeling for persistent organic pollutants (POPS): a feasibility study for Northem Europe. Environ Sci Technol 2007;41(7):2165-71.

Goodchild MF. Geographical information science. Int I Geogr Inf Syst 1992;6(1):31-45.

Götz Christian W, Scheringer Martin, MacLeod Matthew, Roth Christine M, Hungerbühler Konrad. Alterlative apploaches for modeling gas-particle partitioning of semivolatile organic chemicals: model development and comparison. Elvviron Sci Teclinol 2007;41 (4): $1272-8$

Gusev A, Mantseva E, Shatalov V. Stiukov B. Regional multicompartment model MSCEPOP. EMEP/MSC-E technical report 5/2005. www.emep.int.

Haitjema HM. Analytic element modeling of ground water flow. San Diego, CA: Academic Press; 1995.

Hansen JKM, Christensen H, Brandt J, Frohn LM, Geels C. Modelling atmospheric transport of $\alpha$-hexachlorocyclolexane in the Northem Hemisphere with a 3 -d dynamical model: DEHM-POP. Atmos Chem Phys 2004;4:1125-37.

Hollander A, Scheringer $M_{r}$ Shatalov V, Mantseva E, Sweetman A, Roemer M, et al. Estimating overall persistence and long-range taansport potential of persistent organic pollutants: a comparison of seven multimedia mass balance models and atmospheric tansport models. J Elviron Monit 2008; 10:1139-47. doi:10.1039/6803760d.

Hollander A, Cousins I, Amitage J, Hauck M, Huijbregts M, Pistocthi A, van de Meent D. Evaluating the utility of spatially and temporally explicit multimedia fate models. in preparation.

Jaward FM, Farrar NJ, HamerT, Sweetman A], Jones KC. Passive air sampling of PCBs, PBDEs, and organochlorine pesticides across Europe. Environ Sci Technol 2004;38:34-41.

Jolliet 0 . Hauschild $M$. The influence of the intermittent character of rain on fate and long range transport of air organic pollutants. Environ Sod Technol 2005;39(12):4513-22.
Jurado E, Jaward FM, Lohmann R. Jones KC. Simo R, Dachs J. Atmospheric dry deposition of persistent organic pollutants to the Atlantic, and inferences for the global ocean. Environ Sci Technol 2004;38:5505-13

Kalantzi OI, Alcock RE, Johnston PA, Santillo D, Stringer RL. Thomas Go, et al. The global distribution of PCBs and organochlorine pesticides in butter. Environ Sci Technol 2001;35:1013-8.

Karssenberg D. Building dynamic spatial environmental models. Doctor's dissertation, Utrecht University, 2002. Available at http:/igitur-archive.library.uu.nl/dissertations/ 2003-0414-125023/inlioud.litm.

Kohonen T. The self-organizing map. Proc IEEE 1990:78: 1464-80.

Lammel G. Effects of time averaging climate parameters on predicted multicompartmental fate of pesticides and POPs. Environ Pollut 2004:128:291-302.

Lammel G, Klöpffer W, Seemena VS, Schmidt E, Leip A Multicompartmental fate of persistent substances. Comparison of predictions from multimedia box models and a multicompartment chemistry-atmospheric transport model. Environ Sci Pollut Res 2007;14(3):153-65.

Lamon Lara, von Waldow Harald, MacLeod Matthew, Scheringer Martin, Marcomini Antonio, Hungerbhler Konrad. Modeling the global levels and distribution of polychlorinated biphenyls in air under a climate change scenanio. Environmental Science \& Technology Article ASAP: 2009. doi: $10.1021 / e s 900438 \mathrm{j}$.

Larsson MH, Jarvis NJ. A dual-porosity model to quantify macropore flow effects on nitrate leaching. J Environ Oual 1999;28:1298-1307L.

Leip A, Lammel $\mathrm{C}$. Indicators for persistence and long-range transport potential as derived from multicompartment chemistry-transport modeling. Environ Pollut 2004:128(1-2):205-21.

Leistra M, Van Linden AMA, Boesten JJI, Tiktak A, van del Berg F. PEARL model for pesticide behaviour and emissions in soil-plant systems; description of the processes in FoCUS PEARL v.1.1.1. RIVM report 711401009, Alterra rapport 013. Wageningen: Alterra Green World Research; 2001.

Lepom P, Buce Brown, Georg Hanke, Robert Loos, Philippe Quevauviller, Jan Wollgast. Needs for reliable analytical methods for monitoring chemical pollutants in surface water under the European Water Framework Directive. J Chromatogr 2009:1216 (3):302-15 [16 January].

Loos R, Gawlik BM, Locoro G, Rimaviciute E, Contini 5, Bidoglio G. EU-wide survey of polar organic persistent pollutants in European river waters. Environ Pollut 2009;157:561-8.

Mackay D. Multimedia environmental models: the fugacity approach. 2nd ed. New York: Lewis Publishers; 2001. $261 \mathrm{pp}$

Macleod M, Woodfine DG, Mackay D. McKone T, Bemet D, Maddalena R. BETR North America: a regionally segmented multimedia contaminant fate model for North America. Environ Sci Pollut Res 2001;8(3):156-63.

MacLeod M. Riley WJ. McKone TE. Assessing the influence of climate valiability on atmos pheric concentrations of polychlorinated biphenyls using a global-scale mass balance model (BETR-Global). Environ Sci Technol 2005;39:6749-56.

Malisch $R_{+}$Dilara P. PCDD/Fs and PCBs in butter samples from new European Union member states and a candidate country: analytical quality control, results and certain PCB-specific aspects. Chemosphere 2007;67(9):579-89.

Margni M, Pennington DW, Bennet DH, jolliet $O$. Cyclic exchanges and level of coupling between environmental media: intermedia feedback in multimedia fate models, Environ Sci Technol 2004;38:5450-7.

Mejier SN, Ockenden WA, Sweetman A, Breivik K, Glimalt JO, Jones K. Global distribution and budget of PCBs and HCB in background surface soils: implications for sources of environmental processes. Environ Sci Technol 2003:37:667-72.

Montzka Carsten, Calnty Morton, Kreins Peter, Kunkel Ralf, Menz Gunter, Vereecken Harry, et al. Multispectral remotely sensed data in modelling the annual variability of nitrate concentrations in the leachate. Environ Model Softw 2008:23(8):1070-81 (August]

Morton A. Mathematical models: questions of trustwolthiness, Brit. J. Plvil. $5 \mathrm{ci}$ 1993:44:659-74.

Neitsch SL, Arnold JG, Kiniry JR, Williams JR, King KW. Soil and Water Assessment Tool (SWAT) theoretical documentation, version 2000 Grassland, Soil and Water Research Laboratory-Agricultural Research Service. http://www.brctamus.edu/ swat/doc.html 2002 .

Openshaw S, Abrahart SJ. Geocomputation. London: Taylor \& Francis; 2000. 436 pp.

Pennington DW, Margni M. Amman $C$. Jolliet $O$. Multimedia fate and human intake modeling: spatial versus nonspatial insights for chemical emissions in Western Europe. Environ Sci Technol 2005;39:1119-28.

Piineros Garcet JD, Ordonez A. Roosen J, Vanclooster M. Metamodelling: theory, concepts and application to nitrate leaching modeling Ecol Model 2006:193(3-4):629-44 [15 March].

Pistoccli A. Report on multimedia fate and exposure model with various spatial resolutions at the European level, NoMiracle IP D2.4.1 technical report. http:// nomiracle.jrc.it 2005

Pistocchi A. Fate and transport models. In: Melnick E, Everitt B, editors. Encyclopedia of quantitative risk assessment and analysis. Chichester, UK: John Wiley and Sons: 2008a. p. 705-14

Pistocchi A. A GIS-based approach for modeling the fate and tansport of pollutants in Europe. Environ Sci Technol 2008b:42:3640-7.

Pistocchi A. An assessment of soil erosion and freslnwater suspended solid estimates for continental-scale environmental modeling. Hydrol Process 2008c;22 (13):2292-314

Pistocchi A. Bidoglio G. Is it presently possible to assess the spatial distribution of agricultural pesticides for continental Europe? A screening study based on available data, in preparation.

Pistocchi A, Galmarini S. Evaluation of a Simple Spatially Explicit Model of Atmospheric Transport of Pollutants in Europe. Environ Model Assess 2010;15(1):37-51.

Pistocchi A. Pennington D. European hydraulic geometries for continental scale environmental modeling. J Hydrol 2006:329:553-67. 
Pistocchi A. Vizcaino MP. Pennington DW. Alualysis of landscape and climate parameters for continental scale assessment of the fate of pollutants 1018-5593978-92-79-048098; 2006 . EUR 22624 EN

Pistocchi A, Bouraoui F, Bittelli M. A simplified parameterization of the monthly topsoil water budget Water Resour Res 2008;44:W12440. doi:10.1029/2007WR006603.

Pistocchi A, Vizcaino P. Hauck M. A GIS model-based screening of potential contamination of soil and water by pyrethroids in Europe. J Environ Manag 2009;90(11):3410-21. doi:10.1016/j.jelivman.2009.05.020.

Pistocchi A, Groemwold Jan, Lalnr Joost, Loos Mark, Mujica Marelys, Ragas Ad, et al. Mapping cumulative environmental risks from chemical pollution, submitted for publication.

Prevedouros K, MLLeod M, Jones KC, Sweetman A]. Modelling the fate of persistent organic pollutants in Europe: parameterization of a gridded distribution model. Environ Pollut $2004 ; 128: 251-61$.

Ouevauviller P, Borchers U, Gawlik BM. Coordinating links among research, standardization and policy in support of water framework directive clemical monitoring requirements. J Environ Monit 2007;9:915-23.

Roemer M, Baart A, Libre JM. ADEPT: development of an atmospheric deposition and transpolt model fol risk assessment. TNO report B\&O- A R 2005-208, Apeldoorm: 2005.

Sarigiannis D. Soulakellis N, Schäfer K. Tombrou M, Sifakis N, Assimakopoulos D, et al. ICAROS: an integrated computational environment for the assimilation of environmental data and models for urban and regional air quality. Water Air Soil Pollut Focus $2002 ; 2(5): 641-54$

Sarigiannis DA, Soulakellis NA, Sifakis NI. Information fusion for computational assessment of air quality and health effects. Photogramm Eng Remote Sensing 2004;70(2):235-45 [February].

Schaap M, Timmermans RMA, Roemer M, Boersen GAC, Builtjes PJH, Sauter Fl, et al. The LOTOS-EUROS model: description, validation and latest developments. Int J Environ Pollut 2008;32(2):270-90.

Scheringer M, Salzmann M, Stroebe M, Wegmann F, Fenner K, Hungerbuhler K. Long-range transport and global fractionation of POPs: insights from multimedia modeling studies. Environ Pollut0269-7491 2004a;128(1-2):177-88 [Persistant Organic Pollutants, March].

Scheringer M, Salzmann M, Stroebe M, Wegmann F, Fenner K, Hungerbühler K. Long-range transport and global fractionation of pops: insights from multimedia modeling studies. Environ Pollut 2004b;128: 177-88.

Scheringer M, Stroebe M, Wania F, Wegmann F, Hungerbühler K. The effect of export to the deep sea on the long-range transport potential of persistent organic pollutants. Environ Sci Pollut Res 2004c;11(1):41-8.

Sclwwarzenbach RP, Gsclwwend PM, Imboden DM. Envirommental organic chemistry. New Yolk: Wiley: 1993.

Sehili Aissa M, Lammel Gerhard. Global fate and distribution of polycyclic aromatic hydrocarbons emitted from Europe and Russia. Atmos Environ1352-2310 2007:41 (37):8301-15. doi: 10.1016/j.atmosenv.2007.06.050 [December].
Strack ODL Groundwater mechanics, Englewood Cliffs, NJ: Prentice Hall; 1989.

Sukop Michael C. Dispersion in VLEACH and similar models. Ground Water 2001;39 (6): $953-4$.

Suzuki N, Murasawa K, Sakurai T, Nansai K, Matsuhashi K, Moriguchi Y, et al. Georeferenced multimedia environmental fate model (G-CIEMS): model formulation and comparison to the generic model and monitoring approaches. Environ Sci Techno $2004 ; 38(21): 5682-93$.

Tauxe JD. Porous medium advection-dispersion modeling in a geographic information system. Ph.D. diss.: University of Texas, Austin; 1994.

Tiktak A, Boesten JJI, van der Linden AMA, Vanclooster M. Mapping ground water vulnerability to pesticide leacling with a process-based metamodel of EuroPEARL I Environ Oual 2006;35:1213-26.

Tumer DB. Workbook of atmospheric dispersion estimates: an introduction to dispersion modeling. 21nd ed. CRC Press; 1994.

Van Deursen WPA. Geographical Information Systems and Dynamic Models: development and application of a prototype spatial modelling language. Doctor's dissertation, Utrecht University, NGS 190, 1995. Available at http://pcraster.geo.uu. $\mathrm{nl} /$ thesisWvanDeursen.pdf.

Vijayaghavan K, Slell HE, Seigneur C. Practical aspects of using satellite data in air quality modeling. Environ Sti Technol 2008;42:8187-92.

Vizcaino P. Pistocchi A. A simple equation for the spatially explicit prediction of atmospheric concentration of contaminants in Europe: case study on $\gamma-\mathrm{HCH}$, in preparation.

Vizcaino P, Pistocchi A. GIS-based fate modeling of contaminants at Europe-Wide scale: case study on Lindane $(\gamma-\mathrm{HCH})$, in preparation.

von Waldow $\mathrm{H}$. Scheringer $\mathrm{M}$. Hungerbulnler $\mathrm{K}$. Modeled environmental exposure to persistent organic chemicals is independent of the time course of emissions: proof and significance for chemical exposure assessments. Ecol Model 2008;219:256-9.

Wackernagel H. Multivariate geostatistics. Berlin: Springer; 1997.198 pp.

Wania F, Mackay D. A global distribution model for persistent organic chemicals. Sc Total Environ 1995:160/161:211-32.

Wegmann F. The global dynamic multicompartment model CliMoChem for persistent organic pollutants: investigations of the vegetation influence, the cold condensation and the global fractionation. Diss.. Naturwissenschaften, Eidgenössische Technische Hochschule ETH Zürich, Nr. 15427, 2004.

Weiss J. Paepke $O$. Bergman A. A worldwide survey of $\mathrm{PCDD} / \mathrm{F}$ and related contaminants in Butter. Ambio 2005;34(8):589-97 |December|.

Wikipedia article on "Digital Earth": http://en.wikipedia.org/wiki/Digital_Earth.

Zheng $C$. Bennett GD. Applied contaminant transport modeling: theory and practice. Van Nostrand Reinhold: New York: 1995. 